\title{
What Is on the Horizon for Ecophylogenetics?
}

\author{
Diogo B. Provete*
}

Programa de Pós-graduação em Ecologia \& Evolução, Departamento de Ecologia, Instituto de Ciências Biológicas, Universidade Federal de Goiás - UFG, Goiânia, GO, Brasil

\begin{abstract}
A research program in ecophylogenetics integrates phylogenetic hypotheses, trait data, and environmental variables to explain local community assembly. Its core idea lies in the use of phylogenies as a proxy for ecological resemblance among members of a community. This rationale is embodied in the "competition-relatedness hypothesis", which posits that related species are more prone to compete for resources and this process should limit the number of co-occurring species. Concurrently, the research tradition in trait-based community assembly has posed a large importance on the role of environmental filters in determining local species composition. However, despite great methodological advances in the last decade, empirical evidence for the prominence of either process has been mixed. Recent studies have pointed out to the need to test explicitly the assumption of trait conservatism and also to incorporate other mechanisms of species coexistence (e.g., differences in competitive hierarchy and niche segregation) into the basic framework. Here, I review the core ideas of ecophylogenetics and discuss the recent criticism regarding their assumptions and the mechanisms regulating species coexistence. I also highlight recent trends and promising topics. For instance, a phylogenetic approach may be useful in solving long-standing questions in ecology, such as the latitudinal species richness gradient and the relationship biodiversity-ecosystem functioning.
\end{abstract}

Key words: Phylogenetic Community Structure, Species Diversity, Comparative Method, Community Structure, Community Assembly.

\section{"Just as species cannot be considered as statistically independent points to the comparative analyses [...], so a proper understanding of community structure will not be achieved independently of phylogenetic structure." Harvey \& Pagel (1991, p. 204).}

\section{Introduction and Historical Background}

The main goal of ecophylogenetics is to integrate phylogenetic hypotheses and trait-based data to disentangle the contemporary mechanisms driving local community assembly (Webb et al. 2002; Mouquet et al. 2012). Ecophylogenetics as a field of study emerged from the incorporation of phylogenies into studies addressing the role of history and regional processes (Ricklefs 1987) on local community structure in the late 1990s (Webb 2000). As envisaged by Harvey \& Pagel (1991), this trend has changed our understanding of how communities are assembled. However, the idea that common ancestry might affect interspecific relationships and the prominence of eco-evolutionary feedbacks date back to Darwin (1859). In his "The origin of species", Darwin stated that competition would be stronger between pairs of congeners, since

\footnotetext{
${ }^{*}$ Send correspondence to: Diogo B. Provete

Laboratório de Ecologia de Insetos,

Departamento de Ecologia, Instituto de Ciências Biológicas,

Universidade Federal de Goiás - UFG, CP 131,

CEP 74001-970, Goiânia, GO, Brasil

E-mail: dbprovete@gmail.com
}

closely related species would be more similar and overlap in resource use. Therefore, competition would be a strong ecological process limiting the number of co-occurring related species in a habitat.

This idea was further operationalized by Elton (1946), who analyzed the taxonomic clustering in communities through the genus:species ratio (see also Gotelli \& Graves 1996; Vamosi et al. 2009). The underlying idea was that communities structured by competition would have few congeneric species, since the superior competitor would exclude the others (see also Gause 1934). This approach generated much debate and fostered the inception of null models in ecology (reviewed in Gotelli \& Graves 1996).

Historical ecology was another trend introduced by Brooks (1985) that incorporated a "tree thinking" into ecology. It consisted in the analysis of interspecific relationships and species distribution with a phylogenetic perspective. Faith (1992) and Clarke \& Warwick (1998) further developed alternative measures of biodiversity that considered phylogenies or taxonomic hierarchies. In particular, Faith's 
PD have been widely used since then to inform conservation practices (reviewed in Vamosi et al. 2009).

These developments culminated in the use of phylogenies to address specific questions regarding local community assembly, a field now called ecophylogenetics (Mouquet et al. 2012). Here I review its recent developments and also draw attention to some issues that emerged in the literature, mainly linking the basic framework proposed by Webb et al. (2002) and the modern species coexistence theory.

\section{Ecophylogenetics and the Ecological Niche Theory}

Perhaps, the most popular research program in ecophylogenetics intends to disentangle two main drivers of local community assembly (Webb et al. 2002): environmental filtering (Weiher \& Keddy 1999) and limiting similarity (Gause 1934; MacArthur \& Levins 1967). One can postulate the influence of these different processes on community assembly by analyzing the composition of local communities, regarding species relatedness, compared to a null expectation (Webb et al. 2002; Kraft et al. 2007). This is done by using information on the genealogical relationships (phylogenies) of species present in a given community as a multivariate proxy for niche space. Species traits change along the evolutionary process, and the resulting pattern leaves its signature in the phylogeny. Thus, if traits dictate how species use resources and interact with each other, the set of traits shared by species in a community can mirror their ecological similarity. Webb et al. (2002) first proposed that if trait distance correlates with phylogenetic distance, i.e., if closely related species are indeed more similar, a phylogeny could be used as a proxy for overall ecological similarity.

The extension of Webb et al.'s framework proposes that environmental variables on one hand tend to constrain community membership to species with certain traits that allow them to survive under specific environmental conditions (Weiher \& Keddy 1999). Thus, if communities were composed of species more closely related than expected at random (i.e., phylogenetic clustering), it would suggest that environmental filtering is playing a stronger role than competition in dictating community assembly (Webb et al. 2002). For instance, phylogenetic clustered communities are usually found in harsh environments, such as deserts (Pausas \& Verdú 2010). However, when trait space is strongly bounded (Revell et al. 2008; Burns \& Strauss 2012), species in a community may exhibit trait convergence, i.e., species from different lineages bear similar trait values (Losos 2011). This evolutionary process could arise, for example, as an adaptation in response to environmental pressure, allowing distant-related species to co-occur in a habitat (Losos 2011). In that case, a phylogeny would not mirror trait variation. This stresses the importance of testing for phylogenetic signal in ecologically relevant traits as an initial part of any ecophylogenetic study (see also "the phylogeny as a proxy" controversy below).
On the other hand, the classical theory of limiting similarity (MacArthur \& Levins 1967; Abrams 1983) suggests that the number of co-occurring species in a community is constrained by common patterns of resource use. Based on the premise that a phylogeny is a good proxy for ecological resemblance, related species are expected to have also similar patterns of resource use, and thus are more prone to compete against each other. Therefore, if co-occurring species are more distantly related than expected at random (phylogenetic overdispersion), competition is inferred to be the main force driving community assembly. This reasoning was termed the "competition-relatedness hypothesis" by Cahill et al. (2008). However, the prevalence of these two processes in shaping community assembly is still subjected to debate (Grime 2006; Wilson 2007; Mayfield \& Levine 2010). Furthermore, competition and environmental filtering cannot unequivocally be claimed as the two single processes generating those patterns (see Table 1 in Cavender-Bares et al. 2009). For example, facilitation can also promote the co-occurrence of distantly related species in plants (Pausas \& Verdú 2010) and competition can generate clustering if phylogenetic conserved traits related to competitive ability are more important (Mayfield \& Levine 2010; Figure 1). In addition, the detection of phylogenetic clustering or overdispersion is strongly dependent on the spatial, temporal, and phylogenetic scales of the study (Swenson et al. 2006; Cavender-Bares et al. 2009), since density-dependent species interactions are more likely to influence community assembly at the local or habitat scale, with environmental filtering becoming increasingly important at broader spatial scales, due to biogeographic processes and environmental sorting of lineages (Cavender-Bares et al. 2009).

Accordingly, recent studies (Mayfield \& Levine 2010; Hille Ris Lambers et al. 2012) have also challenged the competitionrelatedness hypothesis, as proposed by Webb et al. (2002). Recent developments in species coexistence theory (reviewed in Chesson 2000) highlight that coexistence mechanisms rely on two main aspects: niche differences (stabilizing mechanisms) and competitive ability (equalizing mechanisms; Chesson 2000). Contrarily, the "competitionrelatedness hypothesis" (Webb et al. 2002) largely ignores that differences in competitive hierarchy between species lead to dramatic changes in species abundance or exclusion only in the absence of niche segregation (Mayfield \& Levine 2010; Hille Ris Lambers et al. 2012). Concurrently, overall similarity among species drives competitive exclusion only if (i) traits measured are related to differences in stabilizing niche differences; (ii) species do not possess an optimal trait value; or (iii) the trait measured really translates into differences in resource uptake or stress tolerance, i.e., fitness differences (Hille Ris Lambers et al. 2012). Thus, similar species can still coexist if their competitive ability is low or equivalent (Adler et al. 2007; Hille Ris Lambers et al. 2012). Additionally, the role of character displacement (Schluter 2000) as a factor mediating coexistence is not usually taken into account. Taken together, the points raised by Mayfield 
Table 1. Short list of software and web sites available for phylogenetic inference.

\begin{tabular}{|c|c|c|}
\hline Resource & Description & Address \\
\hline Genbank & Gene sequences & http://www.ncbi.nlm.nih.gov/genbank/ \\
\hline TreeBase & Source for published phylogenies & $\begin{array}{l}\text { http://www.treebase.org. Can also be searched with } \\
\text { the R packages PhyloOrchard and treebase }\end{array}$ \\
\hline PhyloGrafter & Supertree builder & http://rheum.huh.harvard.edu/pgdemo/default/index \\
\hline 10k trees & Bayesian phylogenies for mamalian orders & http://10ktrees.fas.harvard.edu \\
\hline Tree of Life project & Source for phylogenies & www.tolweb.org/tree \\
\hline DataDryad & Source for published phylogenies & www.datadryad.org \\
\hline TimeTree & Divergence time for a pair of taxa & www.timetree.org \\
\hline DateLife & Divergence time for a pair of taxa & http://datelife.org \\
\hline MAFFT & multiple sequence allignment & http://mafft.cbrc.jp/alignment/server/ \\
\hline Muscle & multiple sequence allignment & http://www.ebi.ac.uk/Tools/msa/muscle/ \\
\hline ClustalW2 & multiple sequence allignment & http://www.ebi.ac.uk/Tools/msa/clustalw2/ \\
\hline RAxML & Phylogenetic reconstruction with maximum likelihood & http://phylobench.vital-it.ch/raxml-bb/ \\
\hline PhyML & Phylogenetic reconstruction with maximum likelihood & http://www.atgc-montpellier.fr/phyml/ \\
\hline Phylocom & Several utilities for ecophylogenetics & http://phylodiversity.net/phylocom \\
\hline Phylomatic & Supertree building & http://phylodiversity.net/phylomatic \\
\hline BEAST & $\begin{array}{l}\text { Software for phylogeny estimation with Bayesian } \\
\text { optimization criteria }\end{array}$ & http://beast.bio.ed.ac.uk/Main_Page \\
\hline Mr. Bayes & $\begin{array}{l}\text { Software for phylogeny estimation with Bayesian } \\
\text { optimization criteria }\end{array}$ & http://mrbayes.sourceforge.net \\
\hline Mesquite & $\begin{array}{l}\text { View, edit, and build a supertree. Several utilities for } \\
\text { trait evolution. }\end{array}$ & http://mesquiteproject.org/mesquite/mesquite.html \\
\hline MEGA 5 & $\begin{array}{l}\text { Software package for phylogeny reconstruction and } \\
\text { multiple sequence allignment }\end{array}$ & http://www.megasoftware.net \\
\hline $\begin{array}{l}\text { CRAN Task view } \\
\text { Phylogenetics }\end{array}$ & $\begin{array}{l}\text { Several R packages used in Phylogenetic and trait } \\
\text { evolution analysis }\end{array}$ & $\begin{array}{l}\text { http://cran.r-project.org/web/views/ } \\
\text { Phylogenetics.html }\end{array}$ \\
\hline TreeRipper & Extract phylogenies from published articles & $\begin{array}{l}\text { http://linnaeus.zoology.gla.ac.uk/ jhughes/ } \\
\text { treeripper/ }\end{array}$ \\
\hline TreeSnatcher & Extract phylogenies from published articles & http://www.cibiv.at/software/treesnatcher/ \\
\hline SuperTree server & Online-based supertree builder & http://genome.cs.iastate.edu/supertree/ \\
\hline & & userdata_analysis/userdata_analysis.html \\
\hline
\end{tabular}

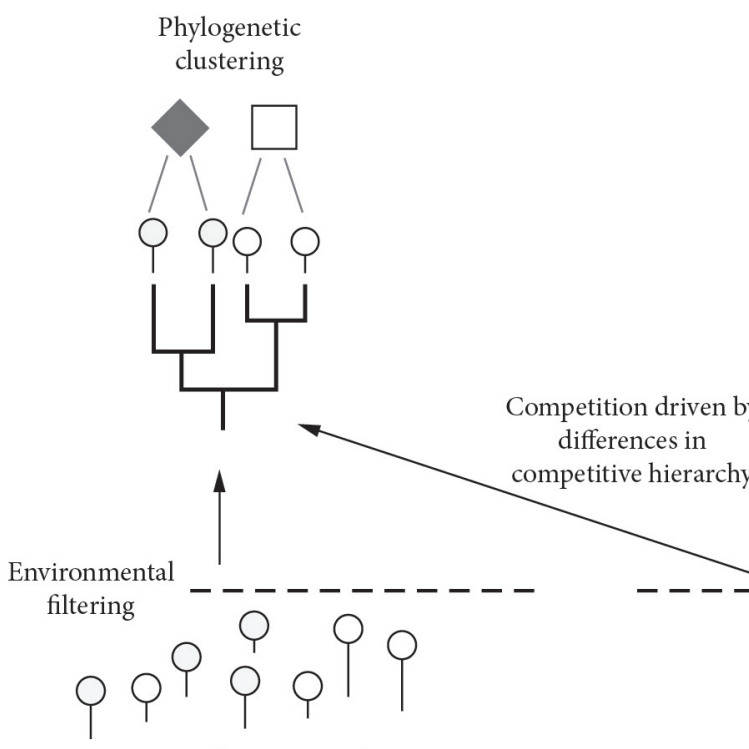

Regional species pool
Phylogenetic overdispersion

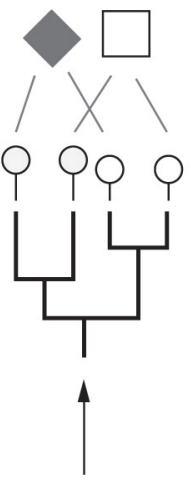

Competition

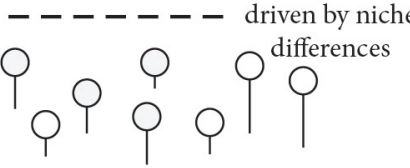

Regional species pool

Figure 1. Different processes can translate into patterns of phylogenetic clustering and overdispersion. In this example, squares and diamonds represent different habitats, dashed line represents the main processes causing the two patterns (competitive exclusion and environmental filtering). However, competition can cause both clustering and overdispersion depending on the phylogenetic signal and the relative strengths of traits related to competitive ability or niche differences. After Mayfield \& Levine (2010). 
\& Levine (2010; reviewed in Hille Ris Lambers et al. 2012) and evidence from an analysis with plants (Cahill et al. 2008) suggest that the "competition-relatedness hypothesis" may not be pervasive. Instead, an integrative approach using experiments to derive vital rates and interaction strengths is needed, which will in turn be used to estimate stabilizing and relative niche differences in groups of co-occurring species (Hille Ris Lambers et al. 2012).

\section{The "Phylogeny as a Proxy" Controversy}

If traits are the entities subjected to environmental filtering or determining competitive exclusion, what is the role of phylogeny? It is difficult (sometimes impossible) to assemble several traits for every species in a community (but see Kraft \& Ackerly 2010). Thus, the idea of using phylogenies in community assembly studies is that it could mirror the variation in a number of traits at the community level. As discussed previously, this concept is at the core of the ecophylogenetics approach (Webb et al. 2002). However, it has been criticized on several grounds (Losos 2011; Graham et al. 2012; Whitfeld et al. 2012). For example, there has been much debate about the meaning of phylogenetic signal and its relationship with phylogenetic niche conservatism (Losos 2008; Cooper et al. 2010). Many tests of phylogenetic signal assume that traits have evolved according to a given evolutionary model, such as Brownian motion (e.g., Blomberg et al. 2003), in which difference in species traits increases linearly with divergence time. Some authors have argued that phylogenetic signal is diagnostic for phylogenetic niche conservatism only under a Brownian motion model (Losos 2008; Cooper et al. 2010). Therefore, recent studies have explicitly tested for phylogenetic signal before assuming that the community phylogeny is a real proxy for traits (e.g., Graham et al. 2012). Yet, many studies have failed to find such correlation (reviewed in Losos 2008, 2011; see also Whitefeld et al. 2012).

However, several evolutionary processes can generate phylogenetic "signal" (Revell et al. 2008) and thus simply detecting a correlation between phylogeny and traits gives us little understanding of which specific evolutionary mechanism is in course. As a result, phylogenetic signal cannot be straightforwardly interpreted, i.e., a low phylogenetic signal (sensu Revell et al. 2008) does not necessarily mean that a trait is evolving at a high evolutionary rate. Instead, methods that incorporate alternative evolutionary models (O’Meara 2012) should be used to test for a correlation between phylogeny and traits. For instance, using Pagel's $\lambda$ (1999) or the $d$ factor to transform branch lengths according to an Ornstein-Uhlenbeck process (Blomberg et al. 2003; reviewed in O’Meara 2012), or even methods that do not explicitly assume an evolutionary model, such as Phylogenetic Eigenvector Regression (PVR), Mantel correlation, and Moran's I (reviewed in Diniz-Filho et al. 2012 and Münkemüller et al. 2012). Additionally, fitting alternative evolutionary models, such as niche filling, Ornstein-Uhlenbeck process, punctuated equilibrium, or
AC/DC (Revell et al. 2008; Cooper et al. 2010; O’Meara 2012) to describe trait variation can also provide relevant information. A straightforward example of this issue is demonstrated by the results of a recent study (Graham et al. 2012) reporting that phylogenetic signal of species traits detected with Blomberg's K did not reflect community organization in relation to traits. Specifically, the authors showed that phylogenetically clustered communities of hummingbirds harbored an even set of traits, yet these traits showed strong phylogenetic signal (Graham et al. 2012).

\section{Intraspecific Trait Variability: the Next Frontier}

Variation in traits within species is ubiquitous in nature (Bolnick et al. 2011) and the primary material for evolution. Phenotypic variation has long been recognized in population genetics as a key mechanism allowing individuals to respond to changing environments. Variation in traits within species may also affect demographic parameters, for instance by allowing individuals to specialize on different prey types, which increases niche width and diminishes intraspecific competition (Bolnick et al. 2011). However, the impact of phenotypic variation on shaping species coexistence and species-environment relationships in ecological communities has only been explored recently.

By incorporating intraspecific trait variability into ecophylogenetics, we can learn how some population processes influence community structure (e.g., Laughlin et al. 2012; Siefert 2012). With the wide availability of databases (e.g., Data Dryad, TRY, LEDA; Table 1), it is now possible to easily recover data about intraspecific trait variation. This perspective seems appealing because individuals are the real entities engaged in interactions in communities.

But how do we include information below the species level into community-wide studies (Cianciaruso et al. 2009)? The first concerns about the use of intraspecific trait variability in evolutionary ecology arose in the context of phylogenetic comparative studies (Ives et al. 2007; Felsenstein 2008). The methodological solution to this issue was to include individuals as polytomies at the species level, with arbitrary short branch lengths (Felsenstein 2008). The same reasoning has been used in studies of functional diversity (Cianciaruso et al. 2009) to build functional dendrograms. However, it would be also appealing to incorporate the genetic distance between natural populations obtained from phylogeographic studies into community phylogenies. This procedure could provide real distances among populations for broad-scales ecophylogenetic studies.

In an exemplar study about the consequences of intraspecific trait variability for the detection of community-wide patterns, Burns \& Strauss (2012) grew 12 focal plant species alone, with conspecifics, and with congeneric species in a series of lath experiments. Species converged to an optimal trait value in harsh environments (Burns \& Strauss 2012; see also Bolnick et al. 2011), due to strong constraints of this 
condition. Authors also found that the ability to detect phylogenetic signal depended not only on the environment but also on the identity of the neighbor plant, i.e., the ability to detect phylogenetic signal was higher for plants growing in stressful environments. However, when species grew in less stressful environments, resource competition led to trait divergence and favored higher intraspecific trait variability, hampering the detection of correlation between traits and the phylogeny. Thus, phenotypic plasticity in response to competitors allows the partitioning of the niche space at fine spatial scales and may be an important factor mediating species coexistence (Burns \& Strauss 2012).

\section{Large Spatiotemporal Scales}

Can phylogenies help to solve one of the longest standing questions in ecology: the latitudinal and altitudinal gradients in species diversity (Wiens \& Donoghue 2004)? Ultimately, only three processes can cause variation in species richness: dispersal, speciation, and extinction (Ricklefs 1987). The tropical niche conservatism hypothesis proposes that most lineages have originated in the tropics, since it has been more stable and larger than temperate regions since the Tertiary. This hypothesis also predicts that tropical regions are more diverse because there has been little time for clades to colonize temperate regions, which coupled with climatic niche conservatism, prevented species from inhabiting temperate environments (Wiens \& Donoghue 2004).

Similarly, a more comprehensive explanation of the diversityclimate relationship may be achieved by incorporating the phylogenetic history of clades. For example, a recent study (Wiens et al. 2011) found that the high richness of hylid tree frogs in Amazonia could be explained by the timing of colonization. This has been called "time for speciation effect" and was also demonstrated in other organisms, including turtles (Stephens \& Wiens 2003), salamanders (Kozak \& Wiens 2012), and bats (Stevens 2011). Additionally, the interaction between time for speciation and regional climatic conditions seems to affect not only the regional but also local richness, since diversification can change the number of species specialized in different habitats along a climatic gradient within a region (Kozak \& Wiens 2012). Such patterns of timing of colonization can only be identified with dated phylogenies, which illustrate the utility of phylogenetic approaches to investigate diversity-climate relationships at multiple scales.

Nevertheless, other scale-dependent spatial processes, such as dispersal limitation (Vamosi et al. 2009; Kissling et al. 2012) have been barely discussed. For example, a recent technique (Peres-Neto et al. 2012) allows partitioning the variation in community phylogenetic structure into environmental and spatial components at multiple scales. By combining multiscale spatial modeling techniques (e.g., Moran's Eigenvector Maps) with Redundancy Analysis, this approach facilitates the analysis of how phylogenetic structure changes with scale in an integrated fashion (Swenson et al. 2006).

\section{Where Do we Go From Here? Advantages and Shortcomings of Ecophylogenetics}

Ecophylogenetics has expanded its scope since the seminal paper of Webb (2000) and now many subdisciplines in ecology have benefited from incorporating a phylogenetic perspective into their toolbox. Biodiversity-ecosystem functioning (B-EF; Srivastava et al. 2012; Mouquet et al. 2012) and interaction networks (Mouquet et al. 2012) are good examples. It seems currently a consensus that the effects of biodiversity on ecosystem functioning are strongly correlated with species traits, since they are involved in how species use available resources and therefore how ecosystem processes are affected (Srivastava et al. 2012). However, similarly to the studies of community phylogenetics, measuring several traits of species in large B-EF experiments is difficult, when not prohibitive (Mouquet et al. 2012). Thus, phylogenetic diversity can be a better proxy for unmeasured overall functional diversity. Similarly, testing for phylogenetic signal in interaction matrices or for species traits related to network degree can have predictive power to indicate which group of species (or lineages) are more likely to interact (via predation, herbivory, or mutualism) with another group (Mouquet et al. 2012). This approach may be promising, since a number of ecologically relevant traits that determine network structure are phylogenetically conserved, such as body size and floral morphology. Nonetheless, phylogenies are expected to have limited usefulness in explaining patterns in multi-trophic communities when traits have a high degree of convergence (Losos 2011).

Furthermore, several limitations still have to be overcome if phylogenies are to be widely used to solve ecological questions, from which the most apparent one is the availability of phylogenies themselves. We know very little about the relationships within certain groups, such as megadiverse arthoropod orders. But apparently, this should not be an impediment, since a recent paper found that the mean pairwise distance among species calculated from a dated phylogeny was more correlated with a "phylogeny" derived from taxonomic hierarchies for angiosperms, than to an undated phylogeny (Ricotta et al. 2012), while the correlation between undated phylogenies and taxonomy was significantly weaker. Authors also found that the lack of branch lengths did not change overall results. This same conclusion seems to apply for some tests of phylogenetic signal (Münkemüller et al. 2012).

Another issue is taxonomic bias. The vast majority of the ecophylogenetics literature deals with plants (Vamosi et al. 2009). This phenomenon is largely due to the availability of user-friendly software (Table 1) to assemble supertrees from plant species lists. However, new phylogenies are being published almost at a daily basis, and other initiatives 
(Table 1) intend to make phylogenies and divergence times available for a wide variety of organisms.

Additionally, the wide availability of web-served software to conduct multiple sequence alignment and large-scale phylogenetic reconstruction allowed people, other than systematists, to reconstruct molecular phylogenies based on published gene sequences (Table 1). Another research avenue was the one opened by Bayesian phylogenetic inference (Huelsenbeck et al. 2001). This approach has already been used in the comparative biology literature (e.g., Pagel and Lutzoni 2002), but was not yet fully explored in ecophylogenetics. The results of any analysis involving phylogenies are dependent on tree topology. However, by incorporating phylogenetic uncertainty via a Bayesian approach we could explicitly include confidence intervals to phylogenetic diversity or measures of phylogenetic structure of local communities.

These are exciting times for community ecology, when the wide availability of data and refinement of theory provide a fresh view to old questions. The developments of ecophylogenetics are an example of how integrative approaches in science can enhance our understanding of the nature of communities and help solving demanding environmental issues in an era of unprecedented global change.

\section{Acknowledgements}

I am grateful to Lilian F. Belussi, Daniel P. Silva, Fabricio Villalobos, and Thiago Gonçalves Souza for critically reading the first version of this manuscript. Thiago Gonçalves Souza also helped with the figure. Carlo Ricotta and an anonymous referee provided valuable suggestions that significantly improved the overall quality of the manuscript. This manuscript is part of my $\mathrm{PhD}$ dissertation at the Ecology and Evolution graduate program at the Federal University of Goiás, and Adriano S. Melo, Marcus V. Cianciaruso, and Thiago F. L. V. B. Rangel provided useful criticism as members of my examination committee. I am supported by a CAPES-DS doctoral fellowship and also received a CAPES-PDSE fellowship (\#18641-12-1) during the final preparation of the manuscript.

\section{References}

Abrams PA, 1983. The theory of limiting similarity. Annual Review of Ecology, Evolution and Systematics, 14:359-376. http://dx.doi.org/10.1146/annurev.es.14.110183.002043

Adler PB, Hille Ris Lambers J \& Levine JM, 2007. A niche for neutrality. Ecology Letters, 10:95-104. PMid:17257097. http:// dx.doi.org/10.1111/j.1461-0248.2006.00996.x

Blomberg SP, Garland TJ \& Ives AR, 2003. Testing for phylogenetic signal in comparative data: behavioral traits are more labile. Evolution, 57:717-745. PMid:12778543.

Bolnick DI et al., 2011. Why intraspecific trait variation matters in community ecology. Trends in Ecology \& Evolution,
26:183-192. PMid:21367482 PMCid:3088364. http://dx.doi. org/10.1016/j.tree.2011.01.009

Brooks DR, 1985. Historical ecology: a new approach to studying the evolution of ecological associations. Annals of the Missouri Botanical Garden, 72:660-680. http://dx.doi. org/10.2307/2399219

Burns JH \& Strauss SY, 2012. Effects of competition on phylogenetic signal and phenotypic plasticity in plant functional traits. Ecology, 93:S126-S137. http://dx.doi. org/10.1890/11-0401.1

Cahill JF et al., 2008. Does phylogenetic relatedness influence the strength of competition among vascular plants? Perspectives in Plant Ecology, Evolution and Systematics, 10:41-50. http:// dx.doi.org/10.1016/j.ppees.2007.10.001

Cavender-Bares J et al., 2009. The merging of community ecology and phylogenetic biology. Ecology Letters, 12:693-715. PMid:19473217. http://dx.doi. org/10.1111/j.1461-0248.2009.01314.x

Chesson P, 2000. Mechanisms of maintenance of species diversity. Annual Review of Ecology and Systematics, 31:343-366. http:// dx.doi.org/10.1146/annurev.ecolsys.31.1.343

Cianciaruso MV et al., 2009. Including intraspecific variability in functional diversity. Ecology, 90:81-89. PMid:19294915. http://dx.doi.org/10.1890/07-1864.1

Clarke K \& Warwick R, 1998. A taxonomic distinctness index and its statistical properties. Journal of Applied Ecology, 35:523531. http://dx.doi.org/10.1046/j.1365-2664.1998.3540523.x

Cooper N, Jetz W \& Freckleton RP, 2010. Phylogenetic comparative approaches for studying niche conservatism. Journal of Evolutionary Biology, 23:2529-2539. PMid:20964782. http://dx.doi.org/10.1111/j.1420-9101.2010.02144.x

Darwin C, 1859. The origin of species by means of natural selection. London: John Murray.

Diniz-Filho JAF et al., 2012. A comparison of metrics for estimating phylogenetic signal under alternative evolutionary models. Genetics and Molecular Biology, 35:673-679. PMid:23055808 PMCid:3459419. http://dx.doi.org/10.1590/ S1415-47572012005000053

Elton C, 1946. Competition and the structure of ecological communities. Journal of Animal Ecology, 15:54-68. http:// dx.doi.org/10.2307/1625

Faith DP, 1992. Conservation evaluation and phylogenetic diversity. Biological Conservation, 61:1-10. http://dx.doi. org/10.1016/0006-3207(92)91201-3

Felsenstein J, 2008. Comparative methods with sampling error and within-species variation: contrasts revisited and revised. American Naturalist, 171:713-725. PMid:18419518. http:// dx.doi.org/10.1086/587525

Gause GF, 1934. The struggle for existence. Baltimore: Williams \& Wilkins. PMid:17821472. http://dx.doi.org/10.5962/ bhl.title.4489

Gotelli NJ \& Graves GR, 1996. Null models in ecology. Washington: Smithsonian Institution Press.

Graham CH et al., 2012. Untangling the influence of ecological and evolutionary factors on trait variation 
across hummingbird assemblages. Ecology, 93:S99-S111. http://dx.doi.org/10.1890/11-0493.1

Grime JP, 2006. Trait convergence and trait divergence in herbaceous plant communities: Mechanisms and consequences. Journal of Vegetation Science, 17:255-260. http://dx.doi.org/10.1111/j.1654-1103.2006.tb02444.x

Harvey PH \& Pagel M, 1991. The comparative method in evolutionary biology. Oxford: Oxford university press.

Hille Ris Lambers J et al., 2012. Rethinking community assembly through the lens of coexistence theory. Annual Review of Ecology, Evolution, and Systematics, 43:227-48. http://dx.doi.org/10.1146/annurev-ecolsys-110411-160411

Huelsenbeck JP et al., 2001. Bayesian inference of phylogeny and its impact on evolutionary biology. Science 294:2310-2314. PMid:11743192. http://dx.doi.org/10.1126/science.1065889

Ives AR, Midford PE \& Garland T, 2007. Within-species variation and measurement error in phylogenetic comparative methods. Systematic Biology, 56:252-270. PMid:17464881. http://dx.doi.org/10.1080/10635150701313830

Kissling WD et al., 2012. Cenozoic imprints on the phylogenetic structure of palm species assemblages worldwide. Proceedings of the National Academy of Sciences USA, 109:7379-7384. PMid:22529387 PMCid:3358898. http://dx.doi.org/10.1073/ pnas.1120467109

Kozak KH \& Wiens JJ, 2012. Phylogeny, ecology, and the origins of climate-richness relationships. Ecology, 93:S167-S181. http://dx.doi.org/10.1890/11-0542.1

Kraft NJB et al., 2007. Trait evolution, community assembly, and the phylogenetic structure of ecological communities. American Naturalist, 170:271-283. PMid:17874377. http:// dx.doi.org/10.1086/519400

Kraft NJB \& Ackerly DD, 2010. Functional trait and phylogenetic tests of community assembly across spatial scales in an Amazonian forest. Ecological Monographs, 80:401-422. http://dx.doi.org/10.1890/09-1672.1

Laughlin DC et al., 2012. A predictive model of community assembly that incorporates intraspecific trait variation. Ecology Letters, 15:1291-1299. PMid:22906233. http:// dx.doi.org/10.1111/j.1461-0248.2012.01852.x

Losos JB, 2008. Phylogenetic niche conservatism, phylogenetic signal and the relationship between phylogenetic relatedness and ecological similarity among species. Ecology Letters, 11:995-1007. PMid:18673385. http:// dx.doi.org/10.1111/j.1461-0248.2008.01229.x

Losos JB, 2011. Seeing the forest for the trees: the limitations of phylogenies in comparative biology. American Naturalist, 177:709-727. PMid:21597249. http://dx.doi. org/10.1086/660020

MacArthur R \& Levins R, 1967. The Limiting similarity, convergence, and divergence of coexisting species. American Naturalist, 101:377-385. http://dx.doi.org/10.1086/282505

Mayfield MM \& Levine JM, 2010. Opposing effects of competitive exclusion on the phylogenetic structure of communities. Ecology Letters, 13:1085-1093. PMid:20576030. http:// dx.doi.org/10.1111/j.1461-0248.2010.01509.x
Mouquet $\mathrm{N}$ et al., 2012. Ecophylogenetics: advances and perspectives. Biological Reviews, 87:769-785. PMid:22432924. http://dx.doi.org/10.1111/j.1469-185X.2012.00224.x

Münkemüller T et al., 2012. How to measure and test phylogenetic signal. Methods in Ecology and Evolution, 3:743756. http://dx.doi.org/10.1111/j.2041-210X.2012.00196.x

O’Meara BC, 2012. Evolutionary inferences from phylogenies: a review of methods. Annual Review of Ecology, Evolution, and Systematics, 43:267-285. http://dx.doi.org/10.1146/ annurev-ecolsys-110411-160331

Pagel M, 1999. Inferring the historical patterns of biological evolution. Nature, 401:877-884. PMid:10553904. http:// dx.doi.org/10.1038/44766

Pagel M \& Lutzoni F, 2002. Accounting for phylogenetic uncertainty in comparative studies of evolution and adaptation. In: Lässig M \& Valleriani A (eds.). Biological Evolution and Statistical Physics. Berlin: Springer. p. 148-161. http://dx.doi.org/10.1007/3-540-45692-9_8

Pausas JG \& Verdú M, 2010. The jungle of methods for evaluating phenotypic and phylogenetic structure of communities. BioScience, 60:614-625. http://dx.doi. org/10.1525/bio.2010.60.8.7

Peres-Neto PR, Leibold MA \& Dray S, 2012. Assessing the effects of spatial contingency and environmental filtering on metacommunity phylogenetics. Ecology, 93:S14-S30. http://dx.doi.org/10.1890/11-0494.1

Revell L, Harmon L \& Collar D, 2008. Phylogenetic signal, evolutionary process, and rate. Systematic Biology 57:591-601. PMid:18709597. http://dx.doi. org/10.1080/10635150802302427

Ricklefs RE, 1987. Community diversity: relative roles of local and regional process. Science, 235:167-171. PMid:17778629. http://dx.doi.org/10.1126/science.235.4785.167

Ricotta C et al., 2012. Computing diversity from dated phylogenies and taxonomic hierarchies: does it make a difference to the conclusions? Oecologia, 170:501-506. PMid:22526936. http://dx.doi.org/10.1007/s00442-012-2318-8

Schluter D, 2000. Ecological character displacement in adaptive radiation. American Naturalist, 156:S4-S16. http://dx.doi. org/10.1086/303412

Siefert A, 2012. Incorporating intraspecific variation in tests of trait-based community assembly. Oecologia, 170:767-775. PMid:22580640. http://dx.doi.org/10.1007/ s00442-012-2351-7

Srivastava DS et al., 2012. Phylogenetic diversity and the functioning of ecosystems. Ecology Letters, 15:637-648. PMid:22583836. http://dx.doi. org/10.1111/j.1461-0248.2012.01795.x

Stephens PR \& Wiens JJ, 2003. Explaining species richness from continents to communities: the time-for-speciation effect in emydid turtles. American Naturalist, 161:112-128. PMid:12650466. http://dx.doi.org/10.1086/345091

Stevens RD, 2011. Relative effects of time for speciation and tropical niche conservatism on the latitudinal diversity gradient of phyllostomid bats. Proceedings of the Royal Society B: Biological Sciences, 278:2528-2536. PMid:21208951 PMCid:3125621. http://dx.doi.org/10.1098/rspb.2010.2341 
Swenson NG et al., 2006. The problem and promise of scale dependency in community phylogenetics. Ecology, 87:2418-2424. http://dx.doi. org/10.1890/0012-9658(2006)87[2418:TPAPOS]2.0.CO;2

Vamosi SM et al., 2009. Emerging patterns in the comparative analysis of phylogenetic community structure. Molecular Ecology, 18:572-592. PMid:19037898. http://dx.doi. org/10.1111/j.1365-294X.2008.04001.X

Webb CO, 2000. Exploring the phylogenetic structure of ecological communities: an example for rain forest trees. American Naturalist 156:145-155. PMid:10856198. http:// dx.doi.org/10.1086/303378

Webb CO et al., 2002. Phylogenies and community ecology. Annual Review of Ecology and Systematics, 33:475-505. http://dx.doi.org/10.1146/annurev.ecolsys.33.010802.150448

Weiher E \& Keddy P, 1999. Assembly rules as general constraints on community composition. In: Weiher E \& Keddy P (eds.).
Ecological assembly rules: perspectives, advances, retreats. Cambridge: Cambridge University Press. p. 251-271. http:// dx.doi.org/10.1017/CBO9780511542237.010

Wiens JJ \& Donoghue MJ, 2004. Historical biogeography, ecology and species richness. Trends in Ecology \& Evolution, 19:639-644. PMid:16701326. http://dx.doi.org/10.1016/j. tree.2004.09.011

Wiens JJ, Pyron RA \& Moen DS, 2011. Phylogenetic origins of local-scale diversity patterns and the causes of Amazonian megadiversity. Ecology Letters, 14:643-652. PMid:21535341. http://dx.doi.org/10.1111/j.1461-0248.2011.01625.x

Whitfeld TJS et al., 2012. Predicting tropical insect herbivore abundance from host plant traits and phylogeny. Ecology, 93:S211-S222. http://dx.doi.org/10.1890/11-0503.1

Wilson JB, 2007. Trait-divergence assembly rules have been demonstrated: Limiting similarity lives! A reply to Grime. Journal of Vegetation Science, 18:451-452. http://dx.doi. org/10.1111/j.1654-1103.2007.tb02557.x

Received: March 2013

First Decision: June 2013

Accepted: June 2013 